\title{
QR Code Based Secure Billing System for Shops using Cued Click Points
}

\author{
Mr. Vikas Nandgaonkar1, Nikita Dongre', Priyanka Giri' ${ }^{1}$, Diksha Hinge², Ankita Kashid²
}

\author{
1NMIET, SPPU, Computer Department, Talegaon Dabhade, Maharashtra, India \\ ${ }^{2}$ NMIET, Computer Department, Talegaon Dabhade, Maharashtra, India
}

\begin{abstract}
How to cite this paper: Mr. Vikas Nandgaonkar | Nikita Dongre | Priyanka Giri | Diksha Hinge | Ankita Kashid "QR Code Based Secure Billing System for Shops using Cued Click Points" Published in International Journal of Trend in Scientific Research and Development

(ijtsrd), ISSN: 2456-

6470, Volume-3 |

Issue-4, June 2019, pp.834-836, URL: https://www.ijtsrd.c om/papers/ijtsrd23 946.pdf

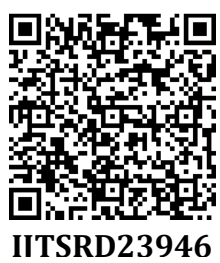

Copyright (C) 2019 by author(s) and International Journal of Trend in Scientific Research and Development Journal. This is an Open Access article distributed under the terms of the Creative Commons

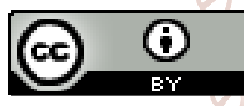
Attribution License (CC BY 4.0) (http://creativecommons.org/licenses/ by $/ 4.0$ )

\section{ABSTRACT}

In today's Mall shopping system, the users usually visit the mall for shopping different products and spend their valuable time in searching the products and the products in their price range. After selecting the product the users have to wait in a long queue for billing which is another time-consuming part of shopping, and moving the cart from one place to another place is another hectic task. In this system the user's time and searching for products in the entire mall increases. So, we are working on this system to avoid these drawbacks. The drawbacks in the existing system are, firstly the time required for bill payment is more as the users have to wait in a long queue. Secondly, the users have to move the cart through the entire mall and carry a load of products at their home. One more drawback is regarding the barcode in which less data is stored. In view of the mobile phone has become popular consumer products, a simple optimization method was given to design shopping guide systems run on smartphones, with the help of QR code generation and recognition technology, wherein, we can store more data using the $\mathrm{QR}$ code. The proposed programs can show accurate and real-time shopping destination, thus help shopping mall to mine customer data more accurately and scientifically. In our system we are going to use QR code for every product using QR code generator, a user goes for shopping and wants to purchase a product, he will scan the QR code of the product using QR code scanner, from his Android device and he will get list of all the similar products in that range and any offers and discounts related to that product, this is done using searching and sorting algorithms. Once the user scans and adds the product to the cart the data gets fed to the server and the bill gets generated after adding all the products to the cart. The bill is sent to the user on his device and the products are delivered home and also bill payment is done online. Nowadays it is difficult to deal with the text-based password. As text can be easily detected, or if it is known then it's risky to deal with such things when we have confidential systems with us. We can overcome this problem with the help of a graphical password with cued click points. This graphical password will be really helpful to secure the confidential systems. Cued click points are the concept in which Persuasive Cued Click points graphical password scheme which includes usability as well as security evaluations. There are a lot of effects that are most well-known about passwords; such as that user cannot memorize complicated passwords which are simple to identify.

Keywords: Mobile Computing, QR code, User Authentication, Graphical Password, Persuasive Cued Click-Points

\section{INTRODUCTION}

Currently, shopping malls are bigger with more abundant goods and more variety of wares. The pursuit of efficient shopping is gradually revealed. To solve the difficulty in customer shopping, large stores have launched mall layout maps, touch Mall shopping systems, and other shopping guide newsletters. In recent years, the shopping guide has become a hot career. To improve the customers shopping experience and to overcome the existing system we developed a system for the ease of customer's shopping. Therefore, building a simple, fast and convenient shopping system has become a mutual concern of merchants and customers. In view of the mobile phone has become a popular consumer product, a simple optimization method was given to design shopping guide systems run on smartphones, with the help of QR code generation and recognition technology, wherein, we can store more data using the QR code. The proposed programs can show accurate and real-time shopping destination, thus help shopping mall to mine customer data more accurately and scientifically. In our system we are going to use QR code for every product using QR code generator, a user goes for shopping and wants to purchase a product, he will scan the QR code of the product using QR code scanner, from his Android device and he will get list of all the similar products 
in that range and any offers and discounts related to that product, this is done using searching and sorting algorithms. Once the user scans and adds the product to the cart the data gets fed to the server and the bill gets generated after adding all the products to the cart. The bill is sent to the user on his device and the products are delivered home and also bill payment is done online.

Once the user scans and adds the product to the cart the data gets fed to the server and the bill gets generated after adding all the products to the cart. Nowadays it is difficult to deal with text-based passwords. As text can be easily detected, or if it is known then it's risky to deal with such things when we have confidential systems with us. We can overcome this problem with the help of a graphical password with cued click points. This graphical password will be really helpful to secure the confidential systems. Cued click points are the concept in which the Persuasive Cued Click points graphical password scheme which includes usability as well as security evaluations.

\section{SCOPE OF THE PROJECT}

$>$ User Experience is made very simple.

$>$ Users don't have to wait at Queue for payment checkout.

$>\quad$ User can pay online bill.

$>$ Detail information about the product will be given to user with offers and discounts and similar products within

$>$ the same price range will be shown.

\section{GOALS AND OBJECTIVES}

$>$ Develop a system for shopping using QR code instead of barcode

$>$ Graphical password is the secured password system, different than traditional text Password system in which user need to select cued click points.

$>$ It is difficult to crack the graphical password. So the system is secured.

$>$ Develop an android app for scanning the QR code of the product and seeing the offers and discounts of the particular product.

$>$ Design a web portal for functionalities like billing system and admin related work.
$>$ Payment option is very fast as compare to waiting queue system.

\section{MOTIVATION}

Barcodes have survived the shift from paper to screen. Printed boarding passes and paper advertisements are substituted by mobile applications and digital billboards where barcodes remain key to exchange small amounts of information in a quick, uncomplicated way. This motivated us to build such a system that can scan a product and its information and based on that information similar products must be displayed. Such system can help the customers in reducing their efforts and time. This precise examination gives a complete and coordinated assessment of PCCP covering both convenience and security issues, to advance understanding as is reasonable before pragmatic organization of new security systems. Through eight client ponders we thought about PCCP to content passwords and two related graphical secret word frameworks. Comes about demonstrate that PCCP is viable at decreasing hotspots (territories of the picture where clients will probably choose click-focuses) and maintaining a strategic distance from designs framed by snap focuses inside a secret word, while as yet looking after ease of use. This is the highly secured system to protect the confidential data.

\section{EXISTING SYSTEM}

In existing mall shopping system, the users usually visit the mall for shopping different products after selecting the product the users have to wait in a long queue for billing which is another time consuming part of shopping. In current framework, client needs to give username and secret key (content watchword), Then OTP will be send on your framework and affirmation will be there. This framework will be at high hazard if other unapproved individual knows the content secret word.

Disadvantages of Existing system:

$>$ The time required for bill payment is more as the users have to wait in a long queue.

One more drawback is regarding the barcode in which less data is stored.

Less payment security






\section{PROPOSED SYSTEM}

The proposed system can be used to show accurate and realtime shopping destination, thus help shopping mall to mine customer data more accurately and scientifically. In our system we are going to use QR code for every product using QR code generator, as user goes for shopping and wants to purchase a product, he will scan the $\mathrm{QR}$ code of the product using QR code scanner, from his android device and he will get list of all the similar products in that range and any offers and discounts related to that product, this is done using searching and sorting algorithms. Once the user scans and adds the product to the cart the data gets feed to the server and the bill gets generated after adding all the products to the cart.

\section{CONCLUSION}

The proposed System can guarantee to increase easiness of shopping in mall or other retail shop by scanning QR code of product and payment security by graphical password scheme using persuasive cued click points.

\section{REFERENCES}

[1] Dynamic Barcodes for a Better Ubiquitous Understanding Geert Vanderhulst and LieveTrappeniers Alcatel-Lucent Bell Labs Copernicuslaan 50, 2018.

[2] Salih Mohammed Salih, "Modified Key Model of Data Encryption Standard," 2010.

[3] Rui Wang, Shuo Chen, Xiao Feng Wang, Shaz Qadeer,How to Shop for Free Online Security Analysis of Cashier-as-a Service Based Web Stores," 2011 IEEE Symposium on Security and Privacy.

[4] Click Passwords under Investigation Warsaw University, Faculty of Psychology, Stawki, International Conference on IEEE, 2012, pp. 11561167.
[5] Alain Forget, Sonia Chiasson, P.C. van Oorschot, Robert Biddle, Improving Text Passwords Through Persuasion, School of Computer Science and Human Oriented Technology Lab Carleton University, Ottawa, Canada, ACM, 2013

[6] Sonia Chiasson, Chris Deschamps, Elizabeth Stobert, Max Hlywa, Bruna Freitas Machado, Alain Forget, Nicholas Wright, Gerry Chan, and Robert Biddle, The MVP Web-based Authentication Framework, in Image Processing, 2012.

[7] Wiedenbeck, Susan, et al. "Design and evaluation of a shoulder-surfing resistant graphical password scheme." Proceedings of the working conference on Advanced visual interfaces. ACM, 2006.

[8] Dirik, Ahmet Emir, Nasir Memon, and Jean-Camille Birget. "Modeling user choice in the PassPoints graphical password scheme." Proceedings of the 3rd symposium on Usable privacy and security. ACM, 2007

[9] Department of Computer Science and Engineering, Department of Computer Technology, Rajiv Gandhi college of Engineering and Research, Wanadongri, Nagpur, Maharashtra, India- "Smart Shopping- An Android Based Shopping Application."

[10] Lei Fu, Department of Computer Engineering , Guangdong Industry Technical college, China"Design of QR-code based Mall Shopping Guide System."

[11] Department of Computer Science and Engineering, Agni College of Technology, India, Department of Computer Science and Engineering, Agni College of Technology, India- "Smart Shopping using QR-code." 